MIDPI

MOL2NET, International Conference Series on Multidisciplinary Sciences

sciforum

\title{
Use of integrated software, applied to the elaboration of didactic material for students with hearing disability at the basic intercultural education center of deaf
}

\author{
Viviana F. Quevedo-Tumailli ${ }^{\text {a, b }}$, Bernabe Ortega-Tenezaca a, b, c, \\ ${ }^{a}$ RNASA-IMEDIR, Computer Science Faculty, University of A Coruña, 15071, A Coruña, Spain. \\ ${ }^{\mathrm{b}}$ Universidad Estatal Amazónica UEA, Puyo, Pastaza, Ecuador \\ ${ }^{c}$ Universidad Regional Autónoma de los Andes UNIANDES-Puyo, Ecuador
}

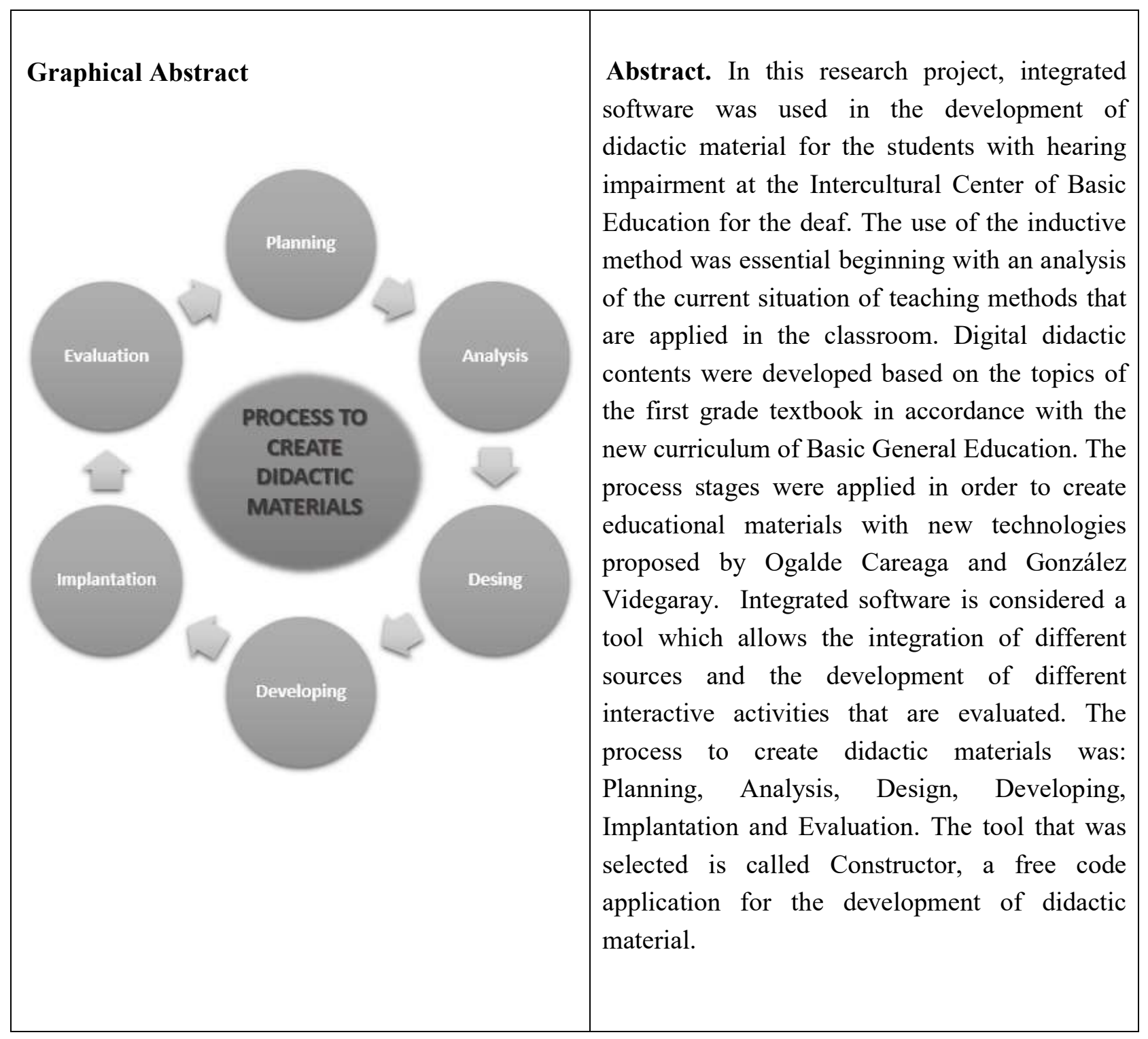




\section{References}

1. Calderón, L. (2012). Dejando Huellas: Primer Año de Educación Básica. Quito, Ecuador: Editorial Prolipa.

2. Camacho, M. (2006). Material didáctico para la Educación Especial (Primera Edición ed.). Costa Rica: Editorial Universidad Estatal a distancia.

3. Carretero, M. (2000). Constructivismo y Educación. México: Progreso: Edit. Luis Vives.

4. Departamento de Educación Especial. Dirección Provincial de Educación del Guayas. Valdez, Luisa. Acepte que el niño tomo su iniciativa. (s. f.). Recuperado 3 de noviembre de 2013, a partir de http://www.educar.ec/noticias/iniciativa.pdf

5. Dr. Perez Marqués Graells. (2011, agosto 7). LOS MEDIOS DIDÁCTICOS. Los medios didácticos y los recursos educativos. Recuperado 3 de septiembre de 2013, a partir de http://peremarques.pangea.org/medios.htm

6. Mena, A. Aportes de la Pedagogía Universal. Habana: Cienfuegos.

7. Murray, T., Blessing, S., \& Ainsworth, S. (2003). Authoring Tools for Advanced Technology Learning Enviroments: Toward cost-effective adaptive, interactive and intelligent educacional software. Dordrecht, The Netherlands: Kluwer Academic Publishers.

8. Ogalde, I., \& Bardavid, E. (2003). Los materiales didácticos: medios y recursos de apoyo a la docencia. México: Trillas.

9. Ogalde, I., \& Maricarmen, G. (2008). Nuevas Tecnologías y Educación: Diseño, desarrollo, uso y evaluación de materiales didácticos (Primera edición ed.). México: Trillas. 